\title{
Ontological Completion in the Adult-Infant System
}

Jonathan Delafield-Butt

Faculty of Humanities and Social Sciences \& Laboratory for Innovation in Autism, University of Strathclyde

jonathan.delafield-butt@strath.ac.uk

\section{PREPRINT IN DRAFT}

COMMENTS WELCOME

$30^{\text {th }}$ December 2018 


\title{
Ontological Completion in the Adult-Infant System
}

\begin{abstract}
In this paper I explore the ontology of the mother-infant system to define moments of physiological and psychological co-operation that form one entity for the completion of 'units of process'. These moments of coupling between mother and infant form ontological wholes with shared consciousness. For example, in the case of extreme, acute neonatal anxiety a process is initiated by the infant requiring co-regulation with an adult other. The adult other provides closure to the process of anxiety, giving ontological completeness to the process. This process of initiation, build, climax, and closure is illustrated by the infant's vocal cry, which parallels the regulatory process. The need for another in this particular processual unit demonstrates the infant in this event is not a distinct entity, but is embedded in a parent-infant system that together forms one unified whole.
\end{abstract}

\section{Keywords}

process ontology, process metaphysics, intersubjectivity, mother-infant dyad, shared consciousness, infant anxiety, containment 


\section{Independence, Interdependence, and Infant Ontology}

The ontological status of a newborn infant is always in flux, it is dynamic. The newborn infant is both an independent entity and an entity dependent on the psychological and physiological properties of a mother (for brevity I refer to all adult care-givers as 'mother'). A newborn infant exists at different times either side of the boundary between independence and dependence on others. The purpose of this paper is to help shed light on the psychological as well as physiological nature of the dynamic coupling and decoupling between infant and mother, and to potentially point to where coupling and de-coupling may go wrong and lead to pathology. To do this, I will describe a process ontology of what it is 'to be', ie. to have a mind, a will, and an existence (Delafield-Butt, 2008; 2009; 2014; Whitehead 1929), and apply this to a very particular category of infant cry, the cry of absolute crisis that occurs commonly in the first three months of life. Both of these topics, the process metaphysic and the existential nature of a newborn crisis, are not well treated in the literature. It is my hope that this novel approach is illuminating both for the philosophy of consciousness as well as for infant psychology, and that there may be some bearing on our understanding of the psychopathological phenomenon of what can be referred to as 'ontological incompleteness' (Stranghellini and Ballerini, 2004), or a rupture in the feeling of wholeness that is derived from completeness. We find this expression in some cases of autism and schizophrenia, in post-natal maternal depression, and sometimes in the experience of the loss of an infant by a parent. This paper speaks more widely to what constitutes an integrated whole subject as it proceeds through time.

It used to be taken for granted that the infant was a distinct and separate entity with her own domain of autonomy quite distinct from that of other, adult minds. However, Sptiz (1945) and Bowlby (1951) showed that psychological intimacy was as vital to the health of infants 
as the primary physical needs of food and shelter. They found that infants who did not have access to normal intimacy failed to thrive and often died. It was not merely the material support of food, warmth, and hygiene that was necessary for the life of a human infant, the full embodiment of human psychological, emotional, and physical 'contact' was apparently also essential. The nature of that contact, between an infant and her mother, has been a focus of study ever since.

From birth, infants demonstrate an agency of basic intentions with depth of feeling expressed through movements of the face, hands, and voice to touch others (Delafield-Butt and Gangopadhyay, 2013; Delafield-Butt et al., 2018; Negayama et al., 2014; Trevarthen et al., 2015; Trevarthen and Delafield-Butt, 2015). They are active, engaging agents with a vital socio-emotional dimension that affects their physiological integrity (Brazelton, 1974; Stern, 1985; Stern, 1971; Trevarthen, 1977; Trevarthen, 1998; Trevarthen and Delafield-Butt, 2013; Delafield-Butt and Trevarthen, 2013). They are responsive to and can discriminate the sound of their mothers' voice (van der Meer and van der Weel, 2011; Decasper and Fifer, 1980) and her odor and from others (Cernoch and Porter, 1985). They engage with others with direct eye contact, facial expressions, and limb and hand movements commensurate with their partner's, and show distinct physiological patterns that prove they expect responses when engaged in dialogue - from their first moments of post-partum life (Meltzoff and Moore, 1977; Nagy, 2008). Infants are conscious, sentient agents (Trevarthen and Delafield-Butt, 2017). They are entities with their own sense of volition and capacity to act out desires, and they are born with the appropriate receptors and effectors to integrate into a social world of thoughts, feelings, and actions. Superficially, the infant looks like a self-contained entity capable of maintaining herself without the aid of others and, at times, she is. Yet, at other times, the infant has explicit need for another to provide for her and it is here where I argue 
her integration with others can become so complete that for a moment, she forms an ontological whole with her mother.

The infant's life oscillates between needs for provision and spans of self-provision. In acting out these phases, I argue the infant becomes psychically joined to another through the sharing of regulatory processes and volitional activity that occur in the same time and in common space with her mother and with shared, co-active physiological activity. One mild example of this is in the shared timing of intention and action in protoconversation co-created between infant and mother (Delafield-Butt and Trevarthen, 2015; Trevarthen and Delafield-Butt, 2013; Trevarthen and Delafield-Butt, 2017). These early, co-created narratives establish higher-order social cognition leading to language and shared meaning (Bruner, 1990). Another, more fundamental kind more intensely charged with vital feeling occurs markedly during moments of intense infant anxiety. I use these moments as a central, illustrative example, because at these points in time unification of mind rises out of its normal ground state to come together to work on controlling an immediate and intense process of psychophysiological importance, with its active feeling dimensions in play in common time and with common regulatory control (Tronick, 2005). Two minds become one.

\section{Voluntary Control, Homeostasis, and Unit Integrity}

The postpartum infant must move her skeletal musculature with guided gestures and must cry out and express feelings to obtain the warmth, food, and security needed for her continued existence. Voluntary control acted in intersubjective, social relations becomes an important mediator of desires and provisioner of needs (Trevarthen et al., 2015). The case is quite different in utero where all needs for existence are provided directly by involuntary physiological processes and the function of the central nervous system plays an ancillary role. The infant in utero has no need to command warmth, attention, food, or other provisions of 
containment. Ex utero the infant's same physiological needs must be provided for through volitional neuromuscular control negotiated through the reciprocal neuromotor actions of adult others. Voluntary motor control becomes a principle mediator in lieu of placental uterine provision. Thus, the intending brains of both infant and mother become primary mediators. The transition from a unified physiological relation between mother and child in utero to one with nervous volitional independence ex utero marks the transition from a basic physiological relationship to one mediated by two thinking and feeling bodies with two central nervous systems that make movements intentional, and that communicate their motives to one another (Trevarthen, Delafield-Butt and Schögler, 2010). However separate these two bodies and brains may be postpartum, the newborn infant alone can only remain viable for short periods of time. It is within the larger infant-adult system that she is able to find the provisions to maintain prolonged 'homeostatic' control to preserve the necessary balance for her health and well-being. As the infant develops, she becomes more autonomous gaining greater self-regulatory capacities. The vital coupling between infant and parent diminishes over these first months and years of life as she 'internalizes', or learns, self-regulatory processes from her experiences of co-regulatory processes enacted with her mother and other caring persons in early life (Feldman et al., 1999; Feldman, 2007). She thus masters a learned ability for self-regulation with newly developed psychophysiological capacities (Fairbairn, 1952).

Still, at birth and in the first months of life, the infant remains in a dynamic waxing and waning relation sometimes more tightly and sometimes more loosely coupled to the mother and in this sense holds properties as one component - not one individual, but one component - in a super-ordinate dyadic system. I argue it is this close relation between infant-andmother that generates the compelling motive in both to act in ways that promote the psychological and physiological integrity of the 'unit' as a whole, and in so doing promotes 
the vital integrity of the 'individuals' within it. There exists a certain force that works to preserve the integrity of the unit. One mechanism of this coupling is through the mirror neuron system that reflects aspects of the mental state of one in the other, enabling direct neural resonance with sympathetic apprehension of the other's state of mind (Gallese, 2007; Rizzolatti and Sinigaglia, 2008). Similarly, the polyvagal system allows direct autonomic coregulation between individuals through the social engagement system (Porges, 2011). Thus, a crisis in the baby can become a crisis reflected in the mother by direct resonance, and not require any additional higher-order mentalization. Her solution to this problem, her means of regulating the crisis both within her and within her baby becomes the same solution for both her and her baby, and her baby learns this.

\section{Processual Units}

I will introduce the notion of a 'processual unit' borrowed from a process metaphysic that treats the ontology of things as units that extend through time with discreet beginnings, developments, and moments of peak excitation before they resolve to satisfaction and are concluded. These ontological units are the basis of Whitehead's process metaphysic (Delafield-Butt, 2008; Whitehead, 1929), where each unit comprises intention, action, and satisfactory conclusion (Delafield-Butt, 2014). This basic ontological unit serves as the basis for one event of 'homeostatic control'. I will illustrate this concept by focusing on the newborn when she is in a particularly heightened state of anxiety where the need for coupling is pronounced and so where both the psychological and physiological character of the coupling is clearly observable. In these cases, the dyadic whole is most clear and the function of each participant to create whole 'processual units' is amplified and made observable. The strength of the coupling can then recede; the infant's life is one of coupling and de-coupling, of forming ontological wholes with others and receding again into ontological wholes with herself in a to-and-fro manner over the course of the day. By 
defining a processual unit and giving measure to its morphology of mutual regulation through an examination of a particular class of infant cry (the most extreme cry of anxiety), this paper better informs our perspective on what constitutes the infant-parent system by identifying where the infant and parent are clearly component parts in a greater ontological entity, and where the infant and parent are distinct individual ontological entities on their own.

When we consider the life of an infant - or any animal for that matter - action stands out as primary processual feature. Sensorimotor control of movement is one of the defining characteristics of mental phenomena (Gibson, 1966; Hurley, 1998; Lee, 2005; Noë, 2004; Delafield-Butt and Gagnopadhyay, 2013; Delafield-Butt, 2014). Any one act contains within it the four essential features of a processual unit: the aim of the subject enacting the movement, the appropriation of sense data and the integration of ongoing sense data during the movement in feed-back control, and the final satisfaction as the goal of the movement is reached and the action concludes to quiescence. The net result of any action is an 'act' of experience that has acquired a new position, and from which the organism can continue onto the next act (Delafield-Butt and Adie, 2016; Delafield-Butt, 2018). Each sensorimotor act is a pearl on the string (Delafield-Butt and Schögler, 2007).

The infant's cry is one such act. Indeed, any vocal utterance by an infant or by an adult, is a discreet unit of sensorimotor activity. Each cry is distinct, each cry is discreet, and each cry is defined by an initiation, build, climax, and conclusion to quiescence. Each cry is an act of experience that places the infant into a new set of relations with her internal and external worlds. Thus, each cry is a step along the walk of life, as all one's actions are. For a life to succeed with health and integrity, these steps must be made with efficient action for completion. Typically, an infant's cry is completed by the infant alone, except in times of very extreme distress when the infant does not complete her cry. These times of peak distress 
and peak anxiety when the infant cannot complete her cry are marked moments when the infant cannot self-regulate and needs the psychophysiological capacities of another, adult individual for closure. The functional presence of the other to close the process means that, in essence, the infant has become coupled, or 'melded', to the other so that together they can be formally viewed as a single ontological entity - for the time it takes to close the anxiety of the infant and return her to her own self-regulated flow of processes.

The case of extreme, acute infant anxiety illustrates the ontological unit and the necessity for an adult in the adult-infant system to give a unit of process closure. In the case of an episode of extreme, acute anxiety, regulation or containment by another is necessary for its satisfactory resolution. Anxiety is a primary human experience and a principal regulatory motive for action (Bowlby, 1973; Spitz, 1950). In infancy, anxiety is transmitted by the cry, a loud and clear indication to listeners that she is distressed and something must be done about it. Her call for help is peculiar, because the infant cannot 'know' in a cognitive sense from past internalized experience that there is another to help. Yet, even the very newborn's cry does just this, it makes a connection with adult others, arouses their autonomic system, and compels them forward to assist (Donoval and Leavitt, 1985). The cry reins them in to give closure to an uncontrolled condition.

The cry presents a very clean, single mode of expression that we may examine, removed from all the other complexes of body movements and autonomic signals. The newborn's anxiety and its communication through the cry are present and prospective feelings and actions. The cry expresses this complex of feeling and in doing so it resonates with listeners who, when acting in sympathy with the infant, will work to make those seemingly worsening changes change for the better. The infant may cry because of an awareness that it cannot manage the internal physiological changes that are happening, either because of their sudden 
and sharp intensity, or because of a diminution in supportive or associated dimensions. These changes can be, for example, a sudden change in her ambients, i.e. temperature, tactility, visuo-acoustics, etc., or its internal 'ambients', ie. nutritional availability, core temperature, somato-intestinal disruptions, etc. Or she may cry because of the absence of another, felt through the associated complexes of acoustic and tactile rhythms and pulses of the heart, breath, and circulatory system, temperature feedback regulation, and the accommodation of body shifts of the self by body shifts of the other. In either case, the anxious newborn cry is usually an expression of the crisis of not managing, of not being able to self-regulate, and of a threat to her vital integrity (Bowlby, 1969; Craig et al., 2000; Fuller, 1991).

The anxious cry provides a solution, because it brings into effect self-regulation by another. The anxious cry recruits the capable regulatory capacity of another to fulfill the function the infant feels he or she cannot fulfill. The cry as an expression of her 'internal', felt experience of life. It is her 'mind-in-action', an outward expression of her very being, just as our observation of her physical body is, and in the case of the cry it is recruiting another body, another capacity to fulfill that which it cannot do alone (Soltis, 2004).

\section{Completion of an Infant's Cry by an Adult}

Infants can attempt to reduce their experience of anxiety through processes of self-regulation enacted by voluntary neuromuscular action. When a newborn infant suffers anxiety, her autonomic and voluntary nervous systems may not have the capacity to bring the crisis under control. The newborn infant may not be familiar enough with the new experiences of an ex utero life to know how to regulate her system or indeed to know in which direction the changes are currently heading. Her inability to self-regulate may feel to her like being propelled into an unknown and uncontrollable future. Anxiety results and she expresses it - 
'express' is derived from the Latin ex- for 'out' and pressare for 'to press', quite literally the infant pushes out her anxiety in voice.

The anxiety is itself a change in circumstances that demands prospective control to bring the organism forward in time to a stable, healthy state. In the infant's incapacity to bring the change under her own control (into a controlled process of change to bring about satisfaction), the infant 'presses out', or one could say 'projects out', this opposite of satisfaction, her primary feeling of dread - a dread of the direction the change is heading in, a dread of the state she is in, a dread of her inability to control the change, or change the state she is in - into an external action, the sound of her cry. Maiello (1995) discusses this feelingin-action as a 'sound object'.

In an attack of acute anxiety, the infant makes her cry by tensing her vocal apparatus to a peak and she holds it there. She produces a loud, tense, high-pitched cry that extends for the duration she has force in her lungs to do so. There is no seeming end in sight to such a cry. It is continuously climaxed and tense; it is intense. Such a cry strikes distress in the listener, so much so that the listener must act, either by removing him or herself from the cry or by doing some action to stop the cry. The sound itself is a fraying process that continues indefinitely, except for the tail of an exasperated lung with no more force for its completion. The infant's cry, true to the infant herself, reflects a state of crisis without the ability for selfcontrol and self-containment. It is an incomplete unit of activity without satisfaction and cessation.

With her cry the infant has initiated a subjective goal to self-regulate to bring herself back to her steady state, her stable, grounded well-being. It is only with the sympathetic completion of this unit in collaboration with the actions of another that the infant can return to a calm 
ground state. The compulsion raised in the other to assist may be due to an inherent recognition of this fraying process, a dislike for it, and a drive to complete the process initiated by the infant. In doing so, the adult holds the infant, brings her close to his or her body, and typically makes soft, repetitive coos counter-balancing the fraying intensities of her cry and bringing her physiology in line with a contained, organized well-being. After successive re-iterations of her cries on the one hand, and the soft coos on the other, altogether with the manifold actions of the body expressing this same anxiety and counter-current through sets of tensions in other muscle groups of the arms, the back, and the face, the infant and the adult begin to calm and her fraying cries begin to subside into hushed sputters until, finally, there is quiet, calm, and restoration of balance.

The final satisfaction and conclusion to the event requires the capabilities and presence of an adult other. Together, the infant and the adult form one complete system that is able to bring the process initiated by the anxiety in the infant and in the mother to a close and so allow this experience of a completed and regulated process to enter into future events as antecedent datum. The process becomes lodged in memory and the means to re-enact it internalized.

The psychoacoustic character of the newborn's cry of distress stands in contrast to her gentle coos, especially those made in a rested and calm state. These latter vocalizations produce soft middles that round into ends that conclude with a gentle drop in intensity. Coos such as these may start off as signs of distress and initiate in the same manner as an anxiety cry, but they are 'contained' by the infant alone and brought to a state of satisfactory conclusion. The rounding of the cry appears to be the result of the infant self-regulating, reflected in the pressing out of the shape of the sound - its gentle rise in intensity, build in the body of the sound - a richness of timbre and pitch - and soft drop in intensity to close. The infant appears organized, satisfied, and even happy. She may play with these sounds. These self- 
concluded coos that initiated as small anxieties appear to be signs of the first self-regulations, or self-containments by the infant. They may also be the first observable signs of internal objects.

\section{Containment, Reciprocity, and Unification}

The capability of a parent to calm a distressed infant simply by holding and cooing softly to her is one of the most remarkable phenomena of early infant-parent life (Bell and Ainsworth, 1972). The effect on both is profound. As the infant calms, her anxious cries begin to cease, her heart and respiratory rate decrease, and she visibly becomes contented. A seeming crisis is averted by the parent simply being there and holding the new child with intuitive sympathetic understanding. So-called 'higher order' adult thoughts that one may bring to this situation are not important, only the being there for the infant is important for the infant, and it is essential (Brazelton, 2006).

The joining together of two individuals in a single reciprocal dyadic system creates between them whole processual units of psychological and physiological mutual regulation, such as in the completion of a process initiation by her cry of distress. The infant is not only an infant, but is subsumed into an infant-mother system. The compulsion by the adult to respond to the infant's anxious cry is a compulsion to satisfy a unit of process that has begun, but in the case of her anxiety is stuck without the capacity for completion, ie. without the capacity for satisfaction and health. It is only with the regulatory elements available from the adult that the process can come to completion and both can advance to a new situation. The engaged adult, being the more capable and responsible element of the system in the infant's anxiety is said to 'contain' the infant (Bion, 1959; Douglas, 2007; Delafield-Butt, 2009). 
It is not surprising that the adult and infant in this intimate engagement make up an ontological entity. Reciprocal systems, of which they are one, are common scaffolds in biological organisms that work as principal organizing features (Freeman, 2000). It is only the physical separation of the baby and adult in two bodies with two distinct brains that causes one to assume the infant is a complete, ontologically distinct entity in her own right. Indeed, this is the paradox of individuation. As one differentiates, one becomes more autonomous with a greater degree of self-regulation, a case illustrated by the impressive caesura of birth, yet one is always dependent on the activities of others and so no absolute autonomy exists.

The life of the fetus joined in amphoteronomic regulation with the mother (Trevarthen et al., 2015) becomes the life of the infant with marked voluntary control made in dialogue with a caring other person, a transition marked by a loss of somatic integration and the consequent deployment of voluntary neural regulations. However, as we have shown and as all mothers and father intuitively know, the baby and her parents remain intimately coupled to each other through shared affective states expressed in common time. Physical separation in space does not exclude a unity of mind, and it is this shared mind that is the felt experience of living together that provides the essential containment for healthy development.

\section{Conclusion: Completion in the Mother-Infant System}

Winnicott's famous phrase, "There is no such thing as an infant" (Winnicott, 1965), is perhaps a little more clear now. In some spans of time over the course of many seconds and minutes the infant is reasonably an entity of its own, but this independence can change quickly to a state where the infant is dependent on and necessarily coupled to, another person for vital regulation and provision. The metaphysics of living process suggest that conscious action is composed of units that initiate toward the subject's aim, build through processes of 
integration and re-integration, climax in satisfaction, and finally conclude to quiescence, leaving their legacy for future occasions as learned process and memory (Sprigge, 1983; Whitehead, 1929). Processes that initiate must find completion, lest they be left dangling.

Interestingly, the anxiety expressed by the infant in her vocal cry reflects an initiated process that has not come to completion. The anxious newborn infant cry is a call for help because it is an incomplete action that opens and retains a peak sonic intensity without drawing down to a controlled quiescence and conclusion. The anxious cry stands in contrast psychologically and acoustically to the contented coo, which is not a call for help because it is a complete action with a clear initiation, build, peak climax of intensity, and conclusion to quiescence. As a thing, the infant's cry is a sonic projection of the infant's internal, mental state. The lack of satisfactory completion to the acute anxiety cry mirrors the lack of satisfaction and conclusion to the infant's self-regulatory processes; it becomes an external expression of her internal crisis. The incomplete process of the anxious cry grates and compels the listener to do what the infant cannot, contain the infant by bringing her regulatory processes to a satisfactory conclusion, thereby completing the incomplete process and bringing to a close this particular episode.

\section{References}

Austin, A M B, \& Peery, J C (1983), 'Analysis of Adult-Neonate Synchrony During Speech and Nonspeech', Perceptual and Motor Skills, 57, 455-459

Bell, S M, \& Ainsworth, M D S (1972), 'Infant Crying and Maternal Responsiveness', Child Development, 43, 1171-1190

Bernstein, N A. (1967). The Co-Ordination and Regulation of Movements. (Oxford: Pergamon Press).

Bion, W R (1959), 'Attacks on Linking', International Journal of Psychoanalysis, 40 
Bowlby, J. (1969). Attachment and Loss Volume I: Attachment. (New York: Basic Books).

Bowlby, J. (1973). Attachment and Loss Volume Ii: Separation, Anxiety, and Anger.

(London: The Hogarth Press).

Brazelton, T B. (1974). 'The Origins of Reciprocity: The Early Mother-Infant Interaction'. In M Lewis, \& L Rosenblum (Eds.), The Effects of the Infant on Its Caregiver. (London: Wiley).

Brazelton, T B. (2006). Touchpoints: Birth to Three. (Cambridge, MA: Da Capo Press).

Bruner, Jerome S. (1990), Acts of Meaning (Cambridge, MA: Harvard University Press).

Cernoch, J M, \& Porter, R H (1985), 'Recognition of Maternal Axillary Odors By Infants', Child Development, 56, 1593-1598

Condon, W S, \& Sander, L W (1974), 'Neonate Movement is Synchronized With Adult Speech: Interactional Participation and Language Acquisition', Science, 183, 99-101

Craig, K D, Gilbert-Macleod, C A, \& Lilley, C M. (2000). 'Crying as an Indicator of Pain in Infants'. In R G Barr, B Hopkins, \& J A Green (Eds.), Cry as a Sign, a Symptom, and a Signal: Clinical Emotional and Developmental Aspects of Infant and Toddler Crying. (pp. 23-40). (London: MacKeith Press).

Decasper, A J, \& Fifer, W P (1980), 'Of Human Bonding -- Newborns Prefer Their Mothers' Voices', Science, 208, 1174-1176

Delafield-Butt, J. (2018), 'The Emotional and Embodied Nature of Human Understanding: Sharing narratives of meaning', in Colwyn Trevarthen, Jonathan Delafield-Butt, and Aline-Wendy Dunlop (eds.), The Child's Curriculum: Working with the natural voices of young children (Oxford: Oxford University Press).

Delafield-Butt, J. T. (2014), 'Process and Action: Whitehead's Ontological Units and Perceptuomotor Control Units.', in S. Koutroufinis (ed.), Life and Process (Berlin/Boston: De Gruyter Ontos), 133-56. 
Delafield-Butt, J. T. (2009), 'Containment and reciprocity in biological systems.', in M Dibben and R Newton (eds.), Applied Process Thought II (Paris: Ontos Verlag).

Delafield-Butt, J. T. (2008), 'Biology.', in M Weber, J Seibt, and N Rescher (eds.), Handbook of Whiteheadian Process Thought. (Paris: Ontos Verlag)

Delafield-Butt, J. and Adie, J. (2016), 'The Embodied Narrative Nature of Learning: Nurture in school', Mind Brain \& Education, 10 (2), 14.

Delafield-Butt, J. T., Freer, Y., Perkins, J., Skulina, D. J., Schögler, B. and Lee, D. N. (2018), 'Prospective organization of neonatal arm movements: A motor foundation of embodied agency, disrupted in premature birth', Developmental Science, 21 (6), e12693.

Delafield-Butt, Jonathan T. and Trevarthen, Colwyn (2015), 'The Ontogenesis of Narrative: From moving to meaning', Frontiers in Psychology, 6.

Delafield-Butt, J. T. and Trevarthen, C. (2013), 'Theories of the development of human communication.', in P Cobley and P. Schultz (eds.), Theories and Models of Communication (Handbook of Communication Science; Berlin/Boston: De Gruyter Mouton), 199-222.

Delafield-Butt, J.T. and Gangopadhyay, N. (2013), 'Sensorimotor intentionality: The origins of intentionality in prospective agent action.', Developmental Review, 33 (4), 399-425.

Delafield-Butt, J. T. and Schögler, B. (2007), 'The ubiquitous nature of tau.', in Pepping. G.-J. and M. Grealy (eds.), Closing the Gap (Hillsdale, NJ: Erlbaum).

Donoval, W L, \& Leavitt, L A. (1985). 'Physiology and Behavior: Parents' Response to the Infant Cry.'. In B M Lester, \& C F Z Boukydis (Eds.), Infant Crying: Theoretical and Research Perspectives. Plenum Press).

Douglas, H. (2007). Containment and Reciprocity: Integrating Psychoanalytic Theory and Child Development Research for Work With Children. (London \& New York: Routledge). 
Fairbairn, W R D. (1952). An Object-Relations Theory of the Personality. (New York: Basic Books).

Feldman, R (2007), 'Parent-Infant Synchrony and the Construction of Shared Timing; Physiological Precursors, Developmental Outcomes, and Risk Conditions.', Journal of Child Psychology and Psychiatry, 48, 329-354

Feldman, R, Greenbaum, C W, \& Yirmiya, N (1999), 'Mother-Infant Affect Synchrony as an Antecedent to the Emergence of Self-Control.', Developmental Psychology, 35, 223-231 Freeman, M (2000), 'Feedback Control of Intercellular Signalling in Development', Nature, 408, 313-319

Fuller, B F (1991), 'Acoustic Discrimination of Three Types of Infant Cries.', Nursing Research, 40, 156-160

Gallese, V (2007), 'Before and Below `Theory of Mind': Embodied Simulation and the Neural Correlates of Social Cognition', Philosophical Transactions of the Royal Society B -Biological Sciences, 362, 659-669

Gibson, J J. (1966). The Senses Considered as Perceptual Systems. (Boston: Houghton Mifflin).

Hurley, S L. (1998). Consciousness in Action. (Cambridge, MA: Harvard University Press). Lee, D N. (2005). 'Tau in Action in Development'. In J J Rieser, J J Lockman, \& C A Nelson (Eds.), Action as an Organiser of Learning. (Hillsdale, New Jersey: Erlbaum).

Leyton, L, Leguen, P, Bunch, D, \& Saling, P M (1992), 'Regulation of Mouse Gamete Interaction By a Sperm Tyrosine Kinase.', Proceedings of the National Academy of Sciences, U.S.A, 89, 11692-11695

Maiello, S (1995), 'The Sound-Object: A Hypothesis About Prenatal Auditory Experience and Memory.', Journal of Child Psychotherapy, 21, 23-41 
van der Meer, A. L. H. and van der Weel, F. R. (2011), 'Auditory Guided Arm and Whole Body Movements in Young Infants', in P Strumillo (ed.), Advances in Sound Localization (InTech).

Meltzoff, A N, \& Moore, M K (1977), 'Imitation of Facial and Manual Gestures By Human Neonates', Science, 198, 75-78

Nagy, E (2008), 'Innate Intersubjectivity: Newborns' Sensitivity to Communication Disturbance', Developmental Psychology, 44, 1779-1784

Negayama, K, Delafield-Butt, J T, Momose, K, Ishijima, K, Kawahara, N, Lux, E, Murphy, A, Konstantinos, K (2015), 'Embodied Intersubjective Engagement in Mother-infant Tactile Communication: A cross-cultural study of Japanese and Scottish mother-infant behaviours during infant pick-up', Frontiers in Psychology, 6.

Noë, A. (2004). Action in Perception. (Cambridge, MA: The MIT Press).

Porges, S. W. (2011), The Polyvagal Theory: Neurophysiological foundations of emotions, attachment, and communication (New York: Norton \& Co.).

Reddy, V. (2008). How Infants Know Minds. (Cambridge, MA: Harvard University Press).

Rizzolatti, G, \& Sinigaglia, C. (2008). Mirrors in the Brain: How Our Minds Share Actions and Emotions. (Oxford: Oxford University Press).

Sherrington, C. (1947). The Integrative Action of the Nervous System (2nd ed.). (Cambridge: Cambridge University Press).

Soltis, J (2004), 'The Signal Functions of Early Infant Crying.', Behavioral and Brain Sciences, 27, 443-490

Spitz, R A (1950), 'Anxiety in Infancy: A Study of Its Manifestation in the First Year of Life', International Journal of Psychoanalysis, 31, 138-145

Sprigge, T. (1983). The Vindication of Absolute Idealism. (Edinburgh: Edinburgh University Press). 
Stern, D. (1985). The Interpersonal World of the Infant. (New York: Basic Books).

Stern, D (1971), 'A Micro-Analysis of Mother-Infant Interaction: Behaviors Regulating Social Contact Between a Mother and Her Three-and-a-Half-Month-Old Twins.', Journal of the American Academy of Child Psychiatry, 10, 507-517

Stranghellini, G, \& Ballerini, M (2004), 'Autism: Disembodied Existence', Philosophy, Psychiatry, and Psychology, 11, 259-268

Trevarthen, C. (1977). 'Descriptive Analysis of Infant Communication Behavior.'. In H R Schaffer (Ed.), Studies in Mother-Infant Interaction: The Loch Lomond Symposium (pp. 227-270). (London: Academic Press).

Trevarthen, C. (1998). 'The Concept and Foundations of Intersubjectivity'. In S Braten (Ed.), Intersubjective Communication and Emotion in Early Ontogeny (pp. 15-46). (Cambridge: Cambridge University Press).

Trevarthen, C. (2009). 'Human Biochronology: On the Source and Functions of 'Musicality". In R Hass, \& V Brandes (Eds.), Music That Works. (Wien \& New York: Springer). Trevarthen, C. and Delafield-Butt, J.T. (2017), 'Intersubjectivity in the Imagination and Feelings of the Infant: Implications for Education in the Early Years', in E. Jayne White and Carmen Dalli (eds.), Under-three Year Olds in Policy and Practice (New York: Springer)

Trevarthen, C. and Delafield-Butt, J. T. (2015), 'The Infant's Creative Vitality, In Projects of Self-Discovery and Shared Meaning: How They Anticipate School, and Make It Fruitful', in Sue Robson and Suzanne Flannery Quinn (eds.), International Handbook of Young Children's Thinking and Understanding (Abingdon, Oxfordshire \& New York: Routledge), 3-18.

Trevarthen C, Aitken, K J, Vandekerckhove, M, Delafield-Butt, J, Nagy, E (2015), 'Collaborative Regulations of Vitality in Early Childhood: Stress in Intimate 
Relationships and Postnatal Psychopathology', Developmental Psychopathology (John Wiley \& Sons, Inc.), 65-126.

Trevarthen, Colwyn and Delafield-Butt, Jonathan T. (2013), 'Biology of Shared Meaning and Language Development: Regulating the Life of Narratives.', in M. Legerstee, D. Haley, and M. Bornstein (eds.), The Infant Mind: Origins of the Social Brain (New York: Guildford Press), 167-199.

Trevarthen, C, Delafield-Butt, J T, \& Schögler, B. (2010). 'Psychobiology of Musical Gesture: Innate Rhythm, Harmony and Melody in Movements of Narration'. In A Gritten, \& E King (Eds.), Music and Gesture Ii. (Aldershot: Ashgate).

Trevarthen, C. and Delafield-Butt, J.T. (2017), 'Development of Consciousness', in Brian Hopkins, Elena Geangu, and Sally Linkenauger (eds.), Cambridge Encyclopedia of Child Development (Cambridge: Cambridge University Press), 821-35.

Tronick, E Z. (2005). 'Why is Connection With Other So Critical? The Formation of Dyadic States of Consciousness and the Expansion of Individuals' States of Consciousness: Coherence Governed Selections and the Co-Creation of Meaning Out of Messy Meaning Making.'. In J Nadel, \& D Muir (Eds.), Emotional Development (pp. 293-316). (Oxford: Oxford University Press).

Tronick, E Z. (1977). 'Structure of Early Face-to-Face Communicative Interactions'. In M Bullowa(pp. 349-372). (Cambridge: Cambridge University Press).

Whitehead, A N. (1929). Process and Reality. (New York: Macmillan).

Winnicott, D. (1965). Maturational Processes and the Facilitating Environment. (New York: International Universities Press). 